\title{
UNCOVERING THE DIFFERENCE: MANAGEMENT OF COLLABORATION IN COMMUNITIES OF PRACTICE AND IN VIRTUAL ENTERPRISES / VIRTUAL ORGANISATIONS
}

\author{
Patricia Wolf ${ }^{1}$, Michael Wunram ${ }^{2}$, Rolando Vargas Vallejos ${ }^{3}$ \\ ${ }^{1}$ Fraunhofer IAO, Nobelstraße 12, 70569 Stuttgart, GERMANY, Patricia.Wolf@iao.fhg.de \\ ${ }^{2}$ BIBA - Bremen Institute of Industrial Technology and Applied Work Science at the University of \\ Bremen, Hochschulring 20, 28359 Bremen, GERMANY, wun@biba.uni-bremen.de \\ ${ }^{3}$ Universidade De Caxias Do Sul, Rua Francisco Getulio Vargas 1130, B. Petropolis \\ CEP 95070-560, Caxias do Sul, BRAZIL, rvvallej@ucs.br
}

\begin{abstract}
There are many interesting articles covering collaboration in Communities of Practices (CoPs) and in Virtual Enterprises (VEs)/Virtual Organisations $(V O s)$. At the same time, until this moment there is no established literature on differences and similarities of collaboration management in both kinds of working structures. Within the foreseen paper, the authors are aiming to review this topic and provide insights in similarities and differences concerning structure, objectives, roles and collaboration management tools of and for CoPs and VEs/VOs. The underlying assumption is that managers of VEs/VOs can learn a lot from the immense literature and knowledge on CoPs as there is a big potential to challenge VEs/VOs through integrating and using management concepts developed in Communities of Practice.

The provided insights will be validated by the results of a study on collaboration in Concurrent Enterprises performed during the IST Project CORMA No 1999-12685, a case study in a successful Brazilian VO (VIRFEBRAS) in the mold and die making industry, management insights from the KnowledgeBoard Community build up and supported by the IST Project European Knowledge Management Forum (European KM Forum) No. 2000-26393 and the results of a PhD study on the implementation of Communities of Practice at DaimlerChrysler.
\end{abstract}

\section{INTRODUCTION}

There is a lot of interesting literature covering either collaboration in Communities of Practices (CoPs) or in Virtual Enterprises (VEs)/Virtual Organisations (VOs). At the same time, until this moment there is no established literature comparing the differences and similarities of collaboration management in both kinds of working 
structures although some authors like KAHLER/RITTENBRUCH (1997) mentioned that VEs "can be understood as a special form of a network community". Within this paper, the authors are going to review this topic and to provide insights on similarities and differences concerning structure, objectives, roles and collaboration management tools of and for CoPs and VEs. The underlying assumption is that managers of VEs/VOs can learn a lot from the immense literature and knowledge on CoPs management as there is a big potential to challenge VEs/VOs through integrating and using management concepts developed in Communities of Practice.

\section{EXISTING THEORIES AND WORK}

As stated above, the existing literature on management of Communities of Practice or Virtual Enterprises/Virtual Organisations is usually covering only one of the working structure but not relying on the similarities and differences between both working structures. As a starting point, the authors will first have a look at definitions and characteristics of CoPs and VEs and thereafter come up with suggestions concerning collaboration management.

Communities of Practice have been defined by SNYDER/WENGER (1999) as "informal groups of people bound by a shared practice related to a set of problems". The members of a CoP typically solve problems, discuss insights, share information, mentor and coach each other, make plans for community activities and develop tools and frameworks. Over time, these mutual interactions and relationships help them to build up a shared body of knowledge and a sense of identity. CoPs can occur in a local or a virtual environment (WOLF 2004). In organisations and networks they mostly represent horizontal expert groups around a specific topic of interest and thus, as HILSE (1999) states, create the social contexts and processes that empower experts to develop collectively problem solutions based on expert and product knowledge. Communities of Practice serve business objectives of organisations by taking ownership of a critical area of knowledge (SNYDER/WENGER 1999).

A Virtual Enterprise is defined by CAMARINHA-MATOS/AFSARMANESH (1999) as "[...] a temporary alliance of enterprises that come together to share skills or core competencies and resources in order to better respond to business opportunities and whose co-operation is supported by computer networks.". They state also, that a Virtual Organisation, "is a concept similar to a virtual enterprise, comprising a network of organizations that share resources and skills to achieve its mission/goal, but not limited to an alliance of enterprises. ... A virtual enterprise is, therefore, a particular case of virtual organization". According to WALTON/WHICKER (1996) one can add that "the Virtual Enterprise consists of a series of co-operating 'nodes' of core competence which form into a supply chain in order to address a specific opportunity in the market place". The need for collaboration of especially Small and Medium Enterprises (SMEs) in Virtual Enterprises arises from a change in the global market environment: CAMARINHA-MATOS/AFSARMANESH (1999) emphasise that the concept of VEs is challenging the way industrial manufacturing systems are planed and managed, and thus SMEs must join skills and resources in order to survive and to gain competitive advantage in a global market environment. VALLEJOS (2000) points out that in this environment, the competition for a market position has increased parallel to the frequency of co-operation between competi- 
tors. Competitors are joining efforts and competencies forming VEs and trying to establish stable relationships through VOs. One of the most important reasons is that the collaborative dynamic of co-operation networks generates valuable innovation.

Comparing these basic theoretical insights into the nature and value proposition of both CoPs and VEs/VOs, it is possible to identify first similarities and differences. The first obvious difference is that CoPs are based on interest, their members are working in organisations and networks on a horizontal topic of interest, while VEs are representing collaboration structures along the supply chain (see figure 1):

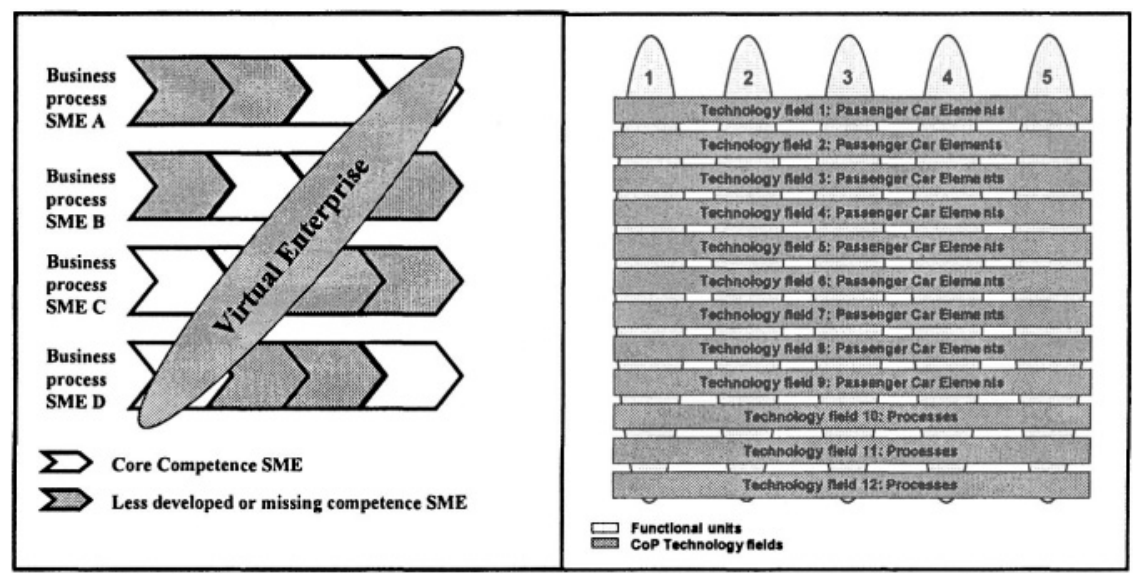

Figure 1: CoPs and VEs as collaborative working structures, adopted from WOLF (2003)

The second obvious difference can be seen in the motivation factor for collaboration: CoPs are usually build up and driven by volunteers, their members have a mutual personal interest on the topic a CoP is working on. Even in the case when CoPs are build up in an organisation by management order - like it happened at the Mercedes-Benz Passenger-Car Development Department-, the basic motivation factor for collaboration among their members is their personal benefit (WOLF, 2003). Only if member benefits like the possibility to participate in a decision process, to get an holistic overview on a specific topic, to use existing synergies etc. are guaranteed, the CoP members are ready to work efficiently on their topic and to contribute by that to the business benefit of the organisation.

Within VEs/VOs, the collaboration is motivated by the need of the participating companies for gaining competitive advantage and to survive in a global economy. The people co-operating in such an environment are representing their organisation and fulfilling specific organisational orders. As co-operation in VEs/VOs happens even between companies that are competitors in specific areas of the value chain, the members have to strive not only for knowledge exchange and transfer but also to hide knowledge covering the core competencies of their own organisation (CAMARINHA-MATOS/AFSARMANESH 1999).

Beside these basic insights in collaboration structure and motivation factors within CoPs and VEs/VOs, it seems to be important to have a focused look at the differences among local and virtual forms of CoPs and to compare them with those 
of Virtual Enterprises in order to understand where VEs can learn from CoPs. Table 1 points out the key characteristics of the three collaboration types ${ }^{1}$ :

Table 1 - Comparison CoPs and VEs/VOs

\begin{tabular}{|c|c|c|c|c|}
\hline & local CoPs & virtual CoPs & VEs & VOs \\
\hline $\begin{array}{l}\text { collaborative } \\
\text { environment }\end{array}$ & face to face & mostly virtually & mostly virtually & mostly virtually \\
\hline duration & long term & long term & short term & $\begin{array}{l}\text { mostly long } \\
\text { term }\end{array}$ \\
\hline structure & fixed & dynamic & dynamic & dynamic \\
\hline participation & $\begin{array}{l}\text { within one or- } \\
\text { ganisation }\end{array}$ & $\begin{array}{l}\text { between or- } \\
\text { ganisations }\end{array}$ & $\begin{array}{l}\text { between or- } \\
\text { ganisations }\end{array}$ & $\begin{array}{l}\text { between or- } \\
\text { ganisations }\end{array}$ \\
\hline $\begin{array}{l}\text { co- } \\
\text { ordination }\end{array}$ & $\begin{array}{l}\text { important, en- } \\
\text { suring life cy- } \\
\text { cle manage- } \\
\text { ment }\end{array}$ & $\begin{array}{l}\text { important, en- } \\
\text { suring life cy- } \\
\text { cle manage- } \\
\text { ment }\end{array}$ & $\begin{array}{l}\text { very important, } \\
\text { ensuring short } \\
\text { term collabora- } \\
\text { tion }\end{array}$ & $\begin{array}{l}\text { important, en- } \\
\text { suring life cy- } \\
\text { cle manage- } \\
\text { ment }\end{array}$ \\
\hline $\begin{array}{l}\text { visibility of } \\
\text { the network } \\
\text { and it's } \\
\text { knowledge to } \\
\text { members }\end{array}$ & $\begin{array}{l}\text { open and trans- } \\
\text { parent, access } \\
\text { to all knowl- } \\
\text { edge and ex- } \\
\text { perts available }\end{array}$ & $\begin{array}{l}\text { open and trans- } \\
\text { parent, access } \\
\text { to all knowl- } \\
\text { edge and ex- } \\
\text { perts available }\end{array}$ & $\begin{array}{l}\text { access to lim- } \\
\text { ited knowledge, } \\
\text { sometimes } \\
\text { visible only on } \\
\text { single level } \\
\text { (between two } \\
\text { 'nodes') } \\
\end{array}$ & $\begin{array}{l}\text { access to lim- } \\
\text { ited knowl- } \\
\text { edge, some- } \\
\text { times visible } \\
\text { only on single } \\
\text { level (between } \\
\text { two 'nodes') } \\
\end{array}$ \\
\hline trust & $\begin{array}{l}\text { key driver for } \\
\text { collaboration }\end{array}$ & $\begin{array}{l}\text { key driver for } \\
\text { collaboration }\end{array}$ & $\begin{array}{l}\text { very important, } \\
\text { but along the } \\
\text { organisational } \\
\text { policy }\end{array}$ & $\begin{array}{l}\text { very important, } \\
\text { but along the } \\
\text { organisational } \\
\text { policy }\end{array}$ \\
\hline role of ICT & $\begin{array}{l}\text { supportive } \\
\text { tools like } \\
\text { knowledge } \\
\text { repositories }\end{array}$ & $\begin{array}{l}\text { very important, } \\
\text { online collabo- } \\
\text { ration through } \\
\text { email, discus- } \\
\text { sion forum, } \\
\text { chat, web con- } \\
\text { ferences }\end{array}$ & $\begin{array}{l}\text { very important, } \\
\text { online collabo- } \\
\text { ration through } \\
\text { email, CAD/ } \\
\text { CAM/CAE/PP } \\
\text { C/CAPP, PDM } \\
\text { systems }\end{array}$ & $\begin{array}{l}\text { very important, } \\
\text { online collabo- } \\
\text { ration through } \\
\text { email, CAD/ } \\
\text { CAM/CAE/PP } \\
\text { C/CAPP, PDM } \\
\text { systems }\end{array}$ \\
\hline
\end{tabular}

From this comparison, it seems obvious that virtual CoPs are closer to VEs and principally to VOs than local CoPs, especially because they seem to have a similar collaboration structure and deal with the same problems: geographical distribution and difference of the (organisational or national) cultures the partners involved belong to. What is special about VEs is their (envisaged) short term duration and the strong influence of organisational policy issues. However, both virtual CoPs and VEs are creating specific social collaboration systems. For VEs, the creation of a

${ }^{1}$ Comparison in Table 1 was done with the help of the arguments stated in all documents in the reference list. 
$\mathrm{VO}$ is proposed by the authors as a good alternative as VOs are more stable and long term oriented. The enterprises involved in such a $\mathrm{VO}$ are able to realize more activities related to education, training, research, etc. to increase their competencies and competitiveness. For that reason, concepts and tools of CoPs and Knowledge Management should be applied in such a context: Collaboration and communication management is the area dedicated to learn from each other.

\section{RESEARCH APPROACH}

What are barriers to collaboration and communication in Virtual Enterprises and virtual communities resulting from heterogeneous organizational/national cultures and geographical distribution? How to overcome them?

Concerning VEs, the authors will use insights gained in a study performed during the IST Project CORMA No 1999-12685. In this project, the identification of barriers to collaboration between organisations in Concurrent Enterprises was one of the major objectives. The outcome of that study were about 70 barriers to collaboration and communication related to human, technological and organisational aspects in the product development process of an $\mathrm{VE}^{2}$.

The data was elevated through semi-structured interviews held within the cooperating companies. In addition to the interviews, and in order to not lose focus, barriers encountered at industrial companies outside the CORMA consortium were also assessed. Furthermore, a case study in the successful Brazilian VO VIRFEBRAS in the mold and die making industry was conducted in order to identify the collaboration barriers in this specific setting (LIMA/VALLEJOS/VARVAKIS 2003).

Concerning collaboration in virtual communities, management insights from the KnowledgeBoard Community build up and supported by the IST Project European Knowledge Management Forum (European KM Forum) No. 2000-26393 will be provided. The KnowledgeBoard is a virtual community platform on Knowledge Management with up to now 5800 registered members from all over the world. Secondly, the results of a $\mathrm{PhD}$ study on the implementation of Communities of Practice at the Mercedes-Benz Passenger Car development from 2000 till 2002 (WOLF, 2003) will be used for identifying and analysing instruments and methods for successful collaboration management in CoPs.

\footnotetext{
${ }^{2}$ The example of this Concurrent Enterprise Study is included as the authors assume that it is possible to identify a continuum of virtual business formats (VEs types) ranging from companies with high virtualness (e.g. companies who are engaged in a predominantly information intensive value chain, have extensive linkages with its environment and operate within a network of diverse and dispersed partners) and very low virtualness (companies engaged in a predominantly physical value chain with a very small co-operative partner network and limited to a single geographical location). Within this continuum of virtualness the Concurrent Enterprise is located somewhere between the middle and the lower end. See WUNRAM/WOLF (2003)
} 


\section{FINDINGS}

As pointed out by the CORMA study, the three most important barriers to collaboration, communication and open knowledge transfer are (WUNRAM/WOLF 2003):

- the fear of exploitation (individuals or organisations are in fear that they wouldn't get anything in return if they share their knowledge),

- refusal of ICT infrastructure use due to e.g. a lack of a common ICT strategy or individuals who are not accustomed to the use of ICT tools and

- problems to deal with international differences as there are language barriers, limited time frame for collaboration, different work styles etc..

Two of these three barriers point on collaboration and communication problems related to different cultures and geographical distribution. Consequently, it seems to be one of the most Critical Success Factors in a VE to establish trustful relationships. The challenging question is how trustworthiness in a virtual short term collaboration can be reached. When we have a short view on collaboration in virtual CoPs, the first thing that becomes obvious is that they do usually not suffer from a problem with trust. How are they able to create that strong feeling of belonging that was developed in both the 25 Special Interest Groups (SIGs) at the KnowledgeBoard and the around $100 \mathrm{CoPs}$ in the Mercedes-Benz Passenger Car development? When analysing this two cases, it becomes obvious that collaborations and trust in CoPs do not arise just by chance but need to be supported by different management activities. In the two described cases the most important management instruments and methods to support trust building and open knowledge sharing have been:

- Reflection: For the members the most important motivation factor have been relevance and passion about the CoP topic. The management at the Mercedes-Benz Passenger Car development department fostered the continuous motivation by providing space for reflection in form of reflection workshops, monitoring and promoting of success stories (WOLF 2003).

- Promotion: Success needs to be valued by externals. The KnowledgeBoard Management team applied for three prices and has won two of them, quotes from thought leaders and practitioners about the benefit of participating in the KnowledgeBoard activities have been published. This activities helped the community to create a spirit of belonging and the work done at the KnowledgeBoard did get a specific value.

- Kick Off: CoPs need support specifically in the start up phase. It is a management task to help the CoP members to develop objectives and visions and working styles. In both of the described case studies the management provided information material and training sessions to the CoP members.

- Knowledge documentation: Virtual communities are in a special need of relying on ICT in collaboration. At the KnowledgeBoard, every CoP member is allowed to use the provided collaboration tools like discussion forum, Q\&A sessions, online chats and web conferencing tool for free. Equally important is that the CoP members get a dedicated space for knowledge capturing. At Mercedes-Benz the CoP members stored their knowledge in 
the so called Engineering Book of Knowledge - a knowledge repository (WOLF 2003).

- Face to face meetings: Even if the above mentioned management methods can support the build up of trust in a virtual CoP, there is a need for face to face meetings. Management should ensure that there is a budget for such activities. The leaders of the special interest groups at the KnowledgeBoard have been sponsored for coming together in face to face workshops or to meet at Knowledge Management Conferences.

- Coordination: Every community, might it be virtual or not, needs a coordinator who takes over responsibility for it's activities, who organises meetings etc. The coordinator should not try to go for a command and control attitude but understanding his own role as facilitator. At the KnowledgeBoard the so-called SIG leaders are playing a key role in the motivation of the members of their SIG and for the planning of common community activities.

What can VEs and VOs learn from this insights about the management of CoPs? Is it possible to apply those methods to organisational short term business collaborations in an virtual environment? The case of VIRFEBRAS shows that this is possible. From the very beginning the members of this VO understood the importance of social relationship and trust building for business success in virtual collaborations. They invested a lot of money into social activities like travelling together to Europe and North America and attending various education courses in their area of collaboration. They developed and still reflect a common vision and the benefits of their collaboration. The VO was supported and coordinated by a Brazilian university who is acting as a mediator between the different companies. Although their collaboration started around a single business opportunity, they are now working together often on different areas, like access to technology, benchmarking techniques to detect and increase their knowledge and best practice in common technical problems, and also upcoming business opportunities. The VIRFEBRAS VO has developed a shared ICT infrastructure supporting collaboration and knowledge capturing in order to broke distance and organisational barriers. (VALLEJOS, 2000). Thus, the VIRFEBRAS case shows that best practices in collaboration management in virtual CoPs can be used in VEs/VOs and lead to a continuous and trustful collaboration process.

\section{CONCLUSIONS}

The VIRFEBRAS case shows that a good alternative for VEs to develop trust and long term relationship between organisations is the creation of VOs. The authors propose that these VOs and also VEs can apply management tools and methods fostering collaboration in virtual CoPs - with slight modifications. Those tools have the tendency to lead the VE - that was build up for a single business opportunity into a continuous virtual collaboration loop. Within this loops, the VE organisations are going through different phases of collaboration in different 'single business opportunities' structuring a VO with CoPs management activities. The establishment of that specific environment allows the build up of trustful relationships and leaves 
at the same time to each company enough flexibility to compete in the same or another area. It seems obvious that this type of management supported VE is providing both to it's members: Autonomy and a feeling of belonging and certainty within a dynamic collaborative working environment.

The best practice in collaboration management presented in the VIRFEBRAS case has not been developed without reflection and several adjustments within the runtime of the VO. As pointed out in the above described example VEs need to be aware from the very beginning that the issue of collaboration management is one of the most important for the success of the collaboration. Learning from virtual communities is definitely one of the possible approaches to set up successful and reflective collaboration management.

\section{REFERENCES}

1. Camarinha-Matos, L.M./ Afsarmanesh, H. (1999), The Virtual Enterprise Concept, in: Camarinha-Matos, L.M./ Afsarmanesh, H. (Editors), Infrastructures for Virtual Enterprises - Networking industrial enterprises, pp 3-15

2. Kahler, H./ Rittenbruch, M., (1997), Community aspects of a Virtual Enterprise, Bonn

3. KnowledgeBoard Community, online at www.knowledgeboard.com

4. Snyder, W./ Wenger, E., (1999), Communities of Practice. Lessons learned from Auburn Hills, DaimlerChrysler Corporate University, Stuttgart

5. Vallejos, R.V. (2000), Virtual Enterprise and Virtual Organisations, Presentation at Caxias do Sul, 08.11.2000

6. Wolf, P. (2003), Erfolgsmessung der Einführung von Wissensmanagement, Eine Evaluationsstudie im Projekt „,Knowledge Management“ der Mercedes-Benz Pkw-Entwicklung der DaimlerChrysler AG, 2003, Münster

7. Wunram, M., Wolf, P. (2003), Barriers to KM between Organisational Cultures in the Face of Concurrent Enterprising: How to Overcome them?; in: Camarinha-Matos, L.M./ Afsarmanesh, H. (Editors), Processes and foundations for virtual organisations, Proceedings of ProVE 2003, Lugano, Switzerland 